\title{
Heavy Cigarette Smokers in a Chinese Population Display a Compromised Permeability Barrier
}

\author{
Shujun Xin, ${ }^{1}$ Li Ye, ${ }^{1}$ George Man, ${ }^{2}$ Chengzhi Lv, ${ }^{1}$ Peter M. Elias, ${ }^{2}$ and Mao-Qiang Man ${ }^{2}$ \\ ${ }^{1}$ Dalian Skin Disease Hospital, Dalian, Liaoning 116021, China \\ ${ }^{2}$ Dermatology Services, San Francisco Veterans Affairs Medical Center and University of California San Francisco, \\ San Francisco, CA 94121, USA
}

Correspondence should be addressed to Chengzhi Lv; dlpfb@126.com and Mao-Qiang Man; mqman@hotmail.com

Received 29 February 2016; Accepted 6 June 2016

Academic Editor: Nikolaos Siafakas

Copyright (C) 2016 Shujun Xin et al. This is an open access article distributed under the Creative Commons Attribution License, which permits unrestricted use, distribution, and reproduction in any medium, provided the original work is properly cited.

\begin{abstract}
Cigarette smoking is associated with various cutaneous disorders with defective permeability. Yet, whether cigarette smoking influences epidermal permeability barrier function is largely unknown. Here, we measured skin biophysical properties, including permeability barrier homeostasis, stratum corneum (SC) integrity, SC hydration, skin surface $\mathrm{pH}$, and skin melanin/erythema index, in cigarette smokers. A total of 99 male volunteers were enrolled in this study. Smokers were categorized as light-tomoderate ( $<20$ cigarettes/day) or heavy smokers ( $\geq 20$ cigarettes/day). An MPA5 was used to measure SC hydration and skin melanin/erythema index on the dorsal hand, forehead, and cheek. Basal transepidermal water loss (TEWL) and barrier recovery rates were assessed on the forearm. A Skin-pH-Meter $\mathrm{pH} 900$ was used to measure skin surface $\mathrm{pH}$. Our results showed that heavy cigarette smokers exhibited delayed barrier recovery after acute abrogation $(1.02 \% \pm 13.06$ versus $16.48 \% \pm 6.07)$, and barrier recovery rates correlated negatively with the number of daily cigarettes consumption $(p=0.0087)$. Changes in biophysical parameters in cigarette smokers varied with body sites. In conclusion, heavy cigarette smokers display compromised permeability barrier homeostasis, which could contribute, in part, to the increased prevalence of certain cutaneous disorders characterized by defective permeability. Thus, improving epidermal permeability barrier should be considered for heavy cigarette smokers.
\end{abstract}

\section{Introduction}

Cigarette smoke negatively impacts human health in multiple organ systems. Previous studies have shown that cigarette smoking inhibits not only sympathetic nerve activity $[1,2]$ but also innate immune responses [3-5]. Clinical studies have also demonstrated that cigarette smoke is a risk factor for developing cardiovascular diseases $[6,7]$ and for death from subclinical coronary atherosclerosis [8]. Additionally, cigarette smoke also increases the risk for developing cancers [9-11] and hip fractures [12-14]. Likewise, cigarette smoking damages renal and liver functions $[15,16]$. Moreover, in utero exposure to cigarette smoking reduces not only the birth weight and length of newborn babies [15], but also lung function, including tidal flow-volume ratios [17-19]. In a murine model, newborn mice also display both liver and spleen abnormalities when their mothers are exposed to cigarette smoke during pregnancy [20]. Finally, altered innate immune responses to both bacterial and viral infections have also been demonstrated following prolonged exposure to cigarette smoke [21-23].

Cigarette smoke also impacts cutaneous function. Cigarette smoke delays cutaneous wound healing [24, 25] and elevates dermal matrix metalloproteinase-8 levels [24]. Epidemiological studies have shown that cigarette smoking increases the incidence of psoriasis [26, 27] and the risk of developing psoriasis is proportional to both the dosage and duration of smoking [27]. Likewise, second-hand cigarette smoking is a significant risk factor for the development of atopic dermatitis in children [28-31].

The development of psoriasis and atopic dermatitis is associated with defective epidermal permeability barrier function $[32,33]$. Studies have demonstrated that nicotine, a major constituent in cigarettes, stimulates keratinocyte differentiation via inducing calcium influx in vitro [34, 35], but calcium influx also delays epidermal permeability 
TABLE 1: Clinical characteristics of subjects.

\begin{tabular}{llccc}
\hline Group & $N$ & Age & Years of smoking & Number of cigarettes/day \\
\hline Nonsmokers & 36 & $53.00 \pm 1.20$ & N/A & N/A \\
All smokers & 63 & $54.21 \pm 0.81$ & $28.79 \pm 1.16$ & $18.03 \pm 1.15$ \\
$\geq 20$ cigarettes/day & 36 & $54.72 \pm 1.04$ & $30.28 \pm 1.18$ & $23.61 \pm 1.27$ \\
$<20$ cigarettes/day & 27 & $53.52 \pm 1.26$ & $26.81 \pm 2.17$ & $10.59 \pm 0.88$ \\
\hline
\end{tabular}

barrier recovery [36]. While these studies together suggest that cigarette smoke compromises epidermal function, the relationship has not yet been assessed. In the present study, we assessed a suite of epidermal functions in smokers versus nonsmokers in a Chinese population.

\section{Subjects and Methods}

2.1. Subjects. A total of 99 male volunteers, including 63

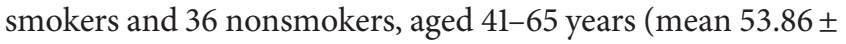
$0.66)$ were enrolled in this study. All were indoor workers with no current skin or systemic diseases, which could influence epidermal barrier function. Smokers were categorized as light-to-moderate ( $<20$ cigarettes/day) or heavy smokers ( $\geq 20$ cigarettes/day). The clinical characteristics of the subjects are detailed in Table 1 . All smokers had smoked for at least 2 years, and were still smoking at the time of the study. No skin care products were applied to measured sites 24 hour prior to taking measurements and the measured sites were not washed with soaps or surfactants for at least 12 hours prior to study.

2.2. Measurements. All measurements were randomly performed by two fully trained dermatologists. TEWL and SC electrical capacitance were measured on the right dorsal hand, right cheek, and forehead with respective probes (TM300 and Corneometer CM825) attached to a CourageKhazaka MPA5 system [37-39]. For stratum corneum integrity assessment, TEWL was measured on the forearm following each D-Squame application for a total of $6 \mathrm{D}$ Squames [37]. For barrier recovery, barrier disruption was achieved by repeated D-Squame applications for a total of 6 D-Squames. TEWL was measured both immediately and 3 hours after the last D-Squame application. A Skin-pHMeter pH900 was used to measure skin surface $\mathrm{pH}$, and melanin/erythema probe connected to MPA5 was used to measure melanin/erythema index. All subjects rested for at least $30 \mathrm{~min}$ at $22-24^{\circ} \mathrm{C}$ at a relative humidity of $45-55 \%$, prior to measurement. This work was performed between October and March at Dalian Skin Disease Hospital, China. The study adhered to the ethical guidelines of the Declaration of Helsinki.

All subjects have been given their informed consent.

2.3. Statistics. GraphPad Prism 4 software was used for all statistical analyses. An unpaired $t$-test with Welch's correction was used for comparisons between two groups. A one-way ANOVA Kruskal-Wallis test with Dunn's multiple comparison was used to determine significances when three or more groups were compared. Linear regression was used to determine the correlation between barrier recovery rates and the amount of daily cigarette consumption. Data are expressed as mean \pm SEM.

\section{Results}

3.1. Heavy Cigarette Smokers Display a Compromised Epidermal Permeability Barrier Homeostasis. We first assessed epidermal permeability barrier homeostasis on the forearm of smokers versus nonsmokers. While there were no differences in basal TEWL between smokers and nonsmokers (Figure 1(a)), permeability barrier recovery accelerated in light cigarette smokers in comparison to nonsmokers (Figure 1(b). $p<0.01$ ), but barrier repair kinetics instead were delayed in heavy cigarette smokers (Figure 1(b)). Notably, permeability barrier recovery rates correlated negatively with the extent of cigarette consumption (Figure 1(c)), but neither basal TEWL nor permeability barrier recovery rates correlated with the number of years that subjects had been smoking (data not shown). Stratum corneum integrity on the dorsal hand was similar between smokers and nonsmokers (Figure 2). Similarly, neither the number of years that subjects had been smoking nor the number of cigarettes smoked daily correlated with stratum corneum integrity (data not shown). These results indicate that heavy cigarette smoking compromises epidermal permeability barrier homeostasis.

3.2. Alterations in Skin Surface $p H$ and Stratum Corneum Hydration on Cigarette Smokers. Since the permeability barrier is closely associated with changes in skin surface $\mathrm{pH}$ and stratum corneum hydration [40-42], we next compared skin surface $\mathrm{pH}$ and stratum corneum hydration in smokers versus nonsmokers. While there were no differences in skin surface $\mathrm{pH}$ between smokers and nonsmokers (Figure 3(a)), stratum corneum hydration on the forehead was significantly higher in light smokers than in nonsmokers (Figure 3(b)). Aside from a significantly higher erythema index on the dorsal hand of heavy cigarette smokers (Figure 3(d)), there were no significant differences in either melanin or erythema indices between smokers and nonsmokers. These results demonstrate that changes in certain skin biophysical properties vary with both body site and the number of cigarettes smoked daily.

\section{Discussion}

Cigarette smoke is a major public health issue, because it is associated with the pathogenesis of a variety of clinical 


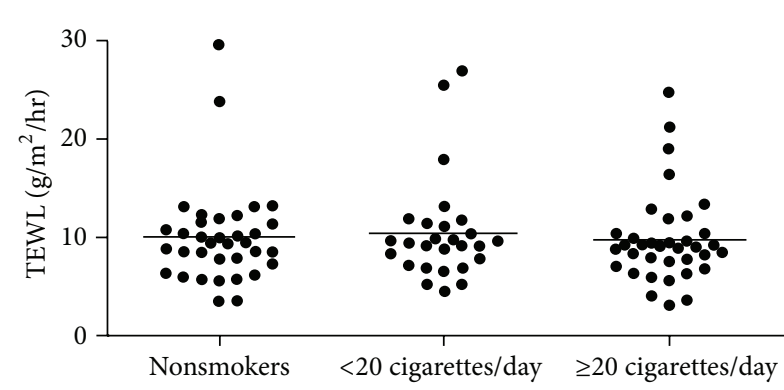

(a)

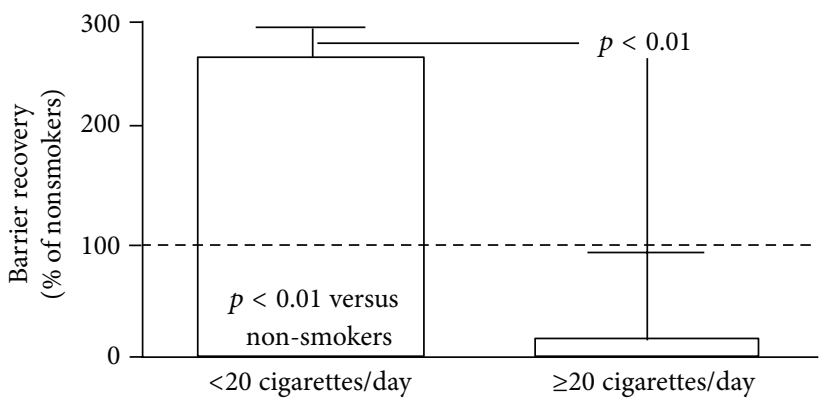

(b)

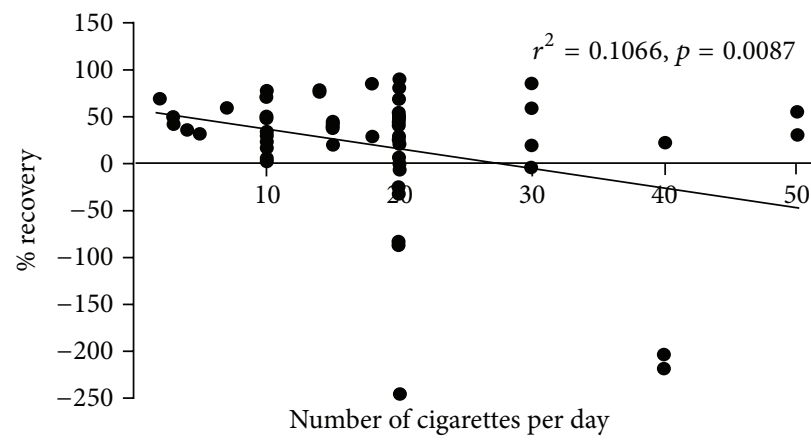

(c)

FIGURE 1: Changes in epidermal permeability barrier function in cigarette smokers. Basal TEWL and barrier repair kinetics on the forearm were determined as described in Subjects and Methods. A one-way ANOVA Kruskal-Wallis test was used to determine significant differences as shown in (a) and (b). (c) shows correlation between barrier recovery rates and the number of cigarettes smoked. The number of subjects in each group is described in Table 1.

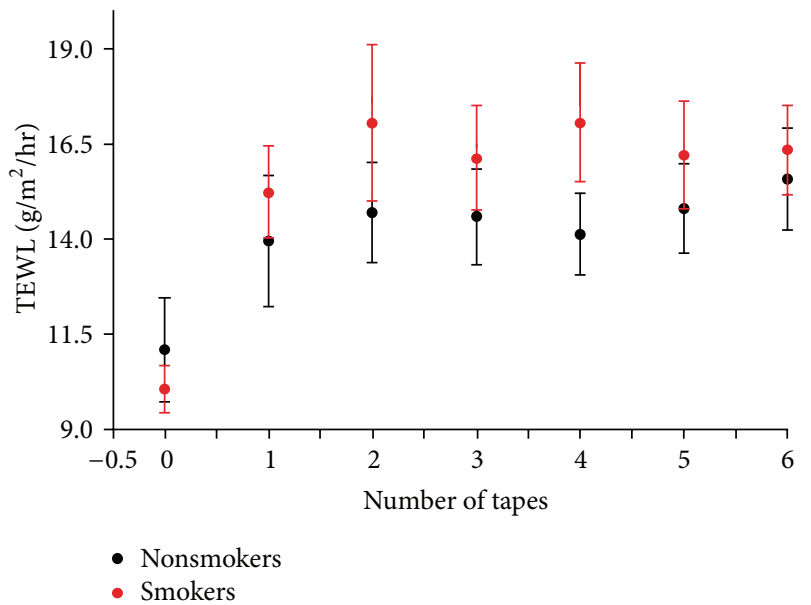

FIGURE 2: Comparison of stratum corneum integrity between smokers and nonsmokers. Stratum corneum integrity on the forearm was assessed by measuring TEWL after each D-Squame application. A total of 6 D-Squames were applied. An unpaired two-tailed Student's $t$-test was used to determine significant differences between smokers and nonsmokers. The number of subjects in each group is detailed in Table 1.

disorders [6-12]. Although the impact of cigarette smoking on certain systemic functions has been extensively studied, the impact of smoking on epidermal permeability barrier function has not yet been well characterized. In the present study, we demonstrated that while basal permeability barrier function remains unchanged, heavy cigarette smokers display altered epidermal permeability barrier homeostasis. Moreover, permeability barrier repair kinetics correlated negatively with the number of cigarettes smoked daily. However, in contrast to the our findings, Muizzuddin et al. found higher basal TEWL levels in cigarette smokers than in nonsmokers [43]. This discrepancy with our data could be attributed to body site differences. It has been demonstrated that skin physiology, including permeability barrier function, vary with the body sites in response to external stressors $[44,45]$. While Muizzuddin et al. measured TEWL on the cheek, we measured TEWL on the forearm. Nevertheless, both studies clearly show that cigarette smoking is associated with compromised permeability barrier homeostasis.

The mechanisms by which cigarette smokers display such diverse differences in permeability barrier homeostasis are not clear. But several studies have shown that nicotine, a major ingredient in cigarettes, regulates keratinocyte functions. Addition of nicotine to keratinocyte cultures increases filaggrin and involucrin expression $[46,47]$ and enhances the formation of cornified envelopes [48]. Moreover, nicotine stimulates keratinocyte adhesion [49]. Administration of nicotine increases cholesterol production in rats [50-52]. These effects of nicotine benefit permeability barrier [35, 53-56]. Thus, these benefits induced by nicotine could be attributable to improved barrier homeostasis in light cigarette 

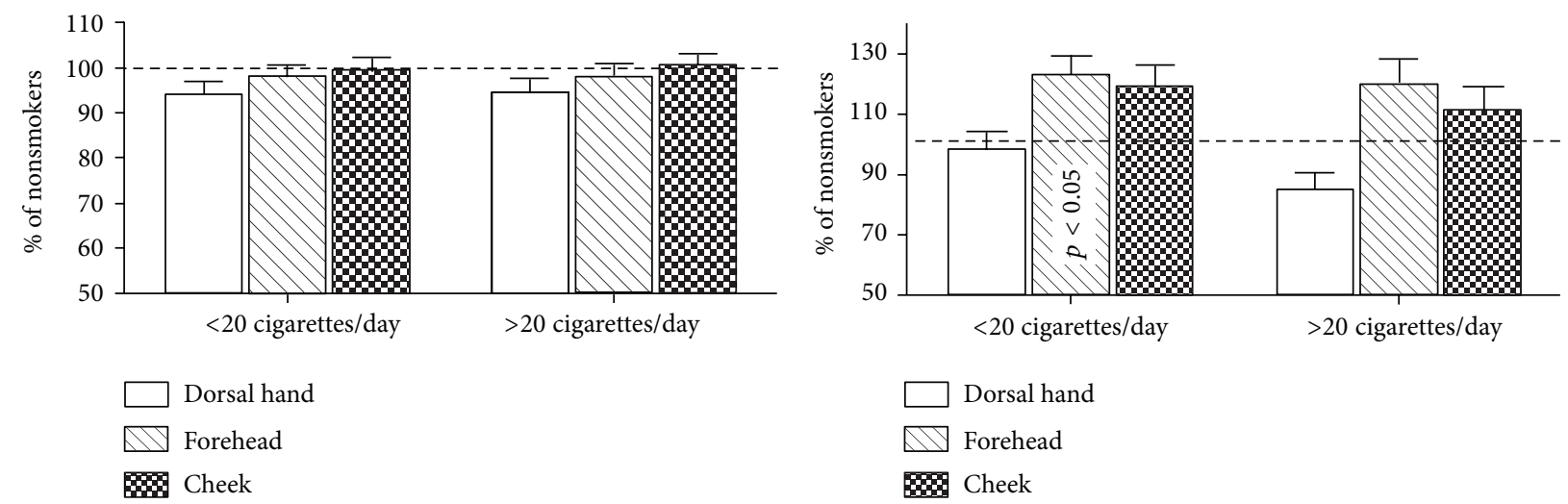

(a)
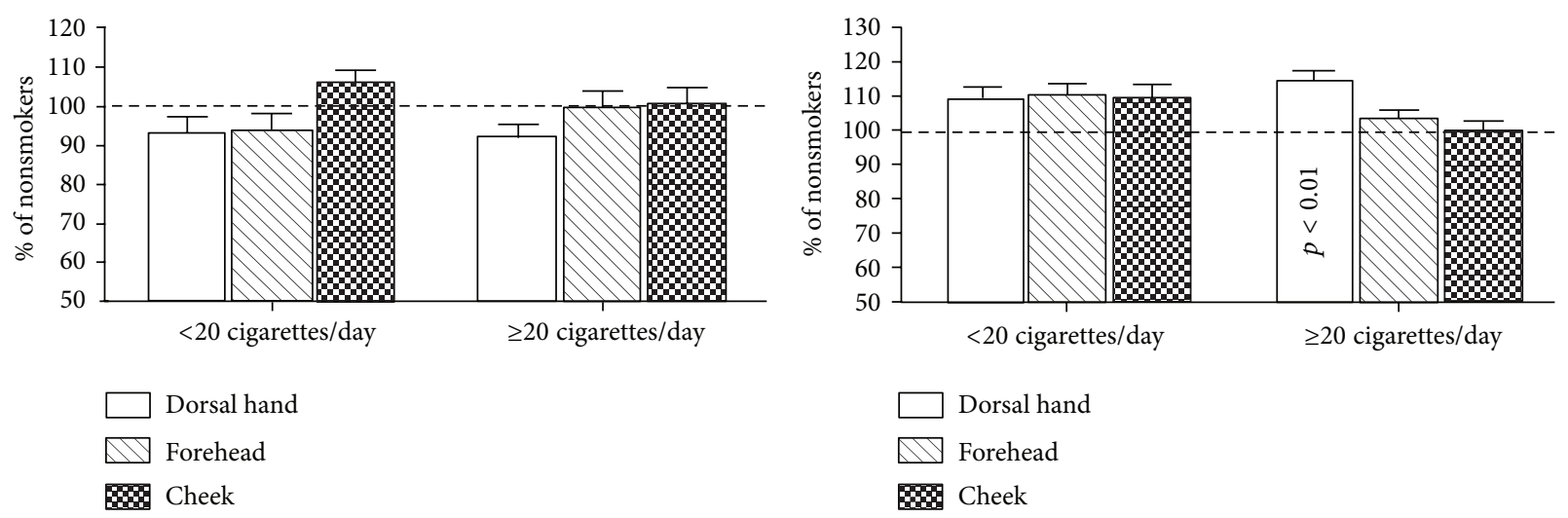

(c)

(d)

FIGURE 3: Comparison of epidermal biophysical properties between smokers and nonsmokers. (a) and (b) depict skin surface pH and stratum corneum hydration, respectively, while (c) and (d) display the melanin and erythema index, respectively. The number of subjects in each group is detailed in Table 1. One-way ANOVA Kruskal-Wallis test was used to determine significant differences between smokers and nonsmokers, and the significances are indicated in the figures.

smokers. On the other hand, nicotine also negatively impacts keratinocyte functions, including the stimulation of both cytokine release [57-59] and oxidative stress [60]. While cytokines can benefit barrier repair [61, 62], if excessive inflammation occurs, it can impair epidermal permeability barrier function $[63,64]$. Likewise, oxidative stress inhibits keratinocyte proliferation and differentiation, as well as HDL receptor expression [65-67], which could result in a defective epidermal permeability barrier homeostasis. Thus, it is likely that the beneficial effects of nicotine-induced keratinocyte differentiation are overridden by the negative effects of excessive amount of cigarette smoking. Clinically, the negative impact of cigarette smoking on epidermal permeability barrier function has significant consequences. A compromised permeability barrier predisposes one to develop dermatitis and psoriasis $[32,33,54,68]$, both of which are associated with certain systemic disorders such as diabetes and cardiovascular diseases [69-72].

The present study also demonstrates that stratum corneum hydration is high on sebaceous gland-enriched sites (the forehead and cheeks) of smokers. This change could reflect increased sebum production, induced by nicotine. A previous study showed that nicotine stimulates sebocyte proliferation and lipid production [73], and we have shown that sebum-originated glycerol is a key determinant of stratum corneum hydration $[74,75]$. In contrast to sebaceous gland-enriched sites, stratum corneum hydration is lower on the dorsal hand of heavy smokers. This could be due to the toxic effects induced by nicotine, because high concentrations of nicotine can inhibit keratinocyte proliferation and protein synthesis $[47,48]$. Collectively, nicotine stimulates sebum production while inhibiting keratinocyte proliferation and protein synthesis. Thus, cigarette smokers display a higher stratum corneum hydration on sebum-enriched sites and a lower stratum corneum hydration on sebum-impoverished sites.

In summary, the present study shows that changes in epidermal permeability barrier homeostasis correlate with the number of cigarettes smoked daily, suggesting a pathogenic role of cigarette smoking in the development of certain cigarette-associated disorders. Therefore, the improvement of epidermal permeability barrier is important for cigarette smokers, particularly heavy smokers.

\section{Competing Interests}

The authors declare that they have no competing interests. 


\section{Authors' Contributions}

Shujun Xin and Li Ye contributed equally to this work.

\section{Acknowledgments}

This work was supported in part by the resources and uses of facilities at the Veterans Affairs Medical Center, San Francisco, California, USA.

\section{References}

[1] K. Narkiewicz, P. J. H. Van De Borne, M. Hausberg et al., "Cigarette smoking increases sympathetic outflow in humans," Circulation, vol. 98, no. 6, pp. 528-534, 1998.

[2] H. R. Middlekauff, J. Park, H. Agrawal, and J. A. Gornbein, "Abnormal sympathetic nerve activity in women exposed to cigarette smoke: a potential mechanism to explain increased cardiac risk," American Journal of Physiology-Heart and Circulatory Physiology, vol. 305, no. 10, pp. H1560-H1567, 2013.

[3] R. Kulkarni, R. Rampersaud, J. L. Aguilar, T. M. Randis, J. L. Kreindler, and A. J. Ratner, "Cigarette smoke inhibits airway epithelial cell innate immune responses to bacteria," Infection and Immunity, vol. 78, no. 5, pp. 2146-2152, 2010.

[4] J. Eddleston, R. U. Lee, A. M. Doerner, J. Herschbach, and B. L. Zuraw, "Cigarette smoke decreases innate responses of epithelial cells to rhinovirus infection," American Journal of Respiratory Cell and Molecular Biology, vol. 44, no. 1, pp. 118126, 2010.

[5] M. A. Modestou, L. J. Manzel, S. El-Mahdy, and D. C. Look, "Inhibition of IFN- $\boldsymbol{\gamma}$-dependent antiviral airway epithelial defense by cigarette smoke," Respiratory Research, vol. 11, article 64, 2010.

[6] J. W. McEvoy, M. J. Blaha, A. P. DeFilippis et al., "Cigarette smoking and cardiovascular events: role of inflammation and subclinical atherosclerosis from the MultiEthnic Study of Atherosclerosis," Arteriosclerosis, Thrombosis, and Vascular Biology, vol. 35, no. 3, pp. 700-709, 2015.

[7] J. W. McEvoy, K. Nasir, A. P. DeFilippis et al., "Relationship of cigarette smoking with inflammation and subclinical vascular disease: the multi-ethnic study of atherosclerosis," Arteriosclerosis, Thrombosis, and Vascular Biology, vol. 35, pp. 1002-1010, 2015.

[8] J. W. McEvoy, M. J. Blaha, J. J. Rivera et al., "Mortality rates in smokers and nonsmokers in the presence or absence of coronary artery calcification," JACC: Cardiovascular Imaging, vol. 5, no. 10, pp. 1037-1045, 2012.

[9] P. R. Band, N. D. Le, R. Fang, and M. Deschamps, "Carcinogenic and endocrine disrupting effects of cigarette smoke and risk of breast cancer," The Lancet, vol. 360, no. 9339, pp. 1044-1049, 2002.

[10] K. C. Johnson, J. Hu, and Y. Mao, "Passive and active smoking and breast cancer risk in Canada, 1994-97," Cancer Causes and Control, vol. 11, no. 3, pp. 211-221, 2000.

[11] P. J. Villeneuve, K. C. Johnson, A. J. G. Hanley, Y. Mao, and Canadian Cancer Registries Epidemiology Research Group, "Alcohol, tobacco and coffee consumption and the risk of pancreatic cancer: results from the Canadian Enhanced Surveillance System case-control project," European Journal of Cancer Prevention, vol. 9, no. 1, pp. 49-58, 2000.
[12] J. A. Baron, B. Y. Farahmand, E. Weiderpass et al., "Cigarette smoking, alcohol consumption, and risk of hip fracture in women," Archives of Internal Medicine, vol. 161, no. 7, pp. 983988, 2001.

[13] J. Cornuz, D. Feskanich, W. C. Willett, and G. A. Colditz, "Smoking, smoking cessation, and risk of hip fracture in women," American Journal of Medicine, vol. 106, no. 3, pp. 311314, 1999.

[14] S. Høidrup, E. Prescott, T. I. Sørensen et al., "Tobacco smoking and risk of hip fracture in men and women," International Journal of Epidemiology, vol. 29, no. 2, pp. 253-259, 2000.

[15] G. Gambaro, F. Verlato, A. Budakovic et al., "Renal impairment in chronic cigarette smokers," Journal of the American Society of Nephrology, vol. 9, no. 4, pp. 562-567, 1998.

[16] J. Altamirano and R. Bataller, "Cigarette smoking and chronic liver diseases," Gut, vol. 59, no. 9, pp. 1159-1162, 2010.

[17] K. C. Lødrup Carlsen, J. J. K. Jaakkola, P. Nafstad, and K.-H. Carlsen, "In utero exposure to cigarette smoking influences lung function at birth," European Respiratory Journal, vol. 10, no. 8, pp. 1774-1779, 1997.

[18] S. M. Stick, P. R. Burton, L. Gurrin, P. D. Sly, and P. N. LeSouëf, "Effects of maternal smoking during pregnancy and a family history of asthma on respiratory function in newborn infants," The Lancet, vol. 348, no. 9034, pp. 1060-1064, 1996.

[19] Y.-F. Li, F. D. Gilliland, K. Berhane et al., "Effects of in utero and environmental tobacco smoke exposure on lung function in boys and girls with and without asthma," American Journal of Respiratory and Critical Care Medicine, vol. 162, no. 6, pp. 20972104, 2000.

[20] M. F. Diniz, V. A. Dourado, and M. E. Silva, "Cigarette smoke causes changes in liver and spleen of mice newborn exposed during pregnancy," Journal of Cytology \& Histology, vol. 4, no. 1, p. 168, 2013.

[21] Y. Feng, Y. Kong, P. F. Barnes et al., "Exposure to cigarette smoke inhibits the pulmonary T-cell response to influenza virus and Mycobacterium tuberculosis," Infection and Immunity, vol. 79, no. 1, pp. 229-237, 2011.

[22] W. Huvenne, E. A. Lanckacker, O. Krysko et al., "Exacerbation of cigarette smoke-induced pulmonary inflammation by Staphylococcus aureus enterotoxin B in mice," Respiratory Research, vol. 12, article 69, 2011.

[23] R. Kulkarni, R. Rampersaud, J. L. Aguilar, T. M. Randis, J. L. Kreindler, and A. J. Ratner, "Cigarette smoke inhibits airway epithelial cell innate immune responses to bacteria," Infection and Immunity, vol. 78, no. 5, pp. 2146-2152, 2010.

[24] L. T. Sørensen, R. Zillmer, M. Ågren, S. Ladelund, T. Karlsmark, and F. Gottrup, "Effect of smoking, abstention, and nicotine patch on epidermal healing and collagenase in skin transudate," Wound Repair and Regeneration, vol. 17, no. 3, pp. 347-353, 2009.

[25] J. E. Siana, S. Rex, and F. Gottrup, "The effect of cigarette smoking on wound healing," Scandinavian Journal of Plastic and Reconstructive Surgery and Hand Surgery, vol. 23, no. 3, pp. 207209, 1989.

[26] A. R. Setty, G. Curhan, and H. K. Choi, "Smoking and the risk of psoriasis in women: nurses' Health Study II," The American Journal of Medicine, vol. 120, no. 11, pp. 953-959, 2007.

[27] W. Li, J. Han, H. K. Choi, and A. A. Qureshi, "Smoking and risk of incident psoriasis among women and men in the United States: a combined analysis," American Journal of Epidemiology, vol. 175, no. 5, pp. 402-413, 2012. 
[28] O. Yi, H.-J. Kwon, H. Kim et al., "Effect of environmental tobacco smoke on atopic dermatitis among children in Korea," Environmental Research, vol. 113, pp. 40-45, 2012.

[29] U. Krämer, C. H. Lemmen, H. Behrendt et al., "The effect of environmental tobacco smoke on eczema and allergic sensitization in children," British Journal of Dermatology, vol. 150, no. 1, pp. 111-118, 2004.

[30] K. Tanaka, Y. Miyake, S. Sasaki, Y. Ohya, and Y. Hirota, "Maternal smoking and environmental tobacco smoke exposure and the risk of allergic diseases in Japanese infants: the Osaka maternal and child health study," Journal of Asthma, vol. 45, no. 9, pp. 833-838, 2008.

[31] C. Raherison, C. Pénard-Morand, D. Moreau et al., "Smoking exposure and allergic sensitization in children according to maternal allergies," Annals of Allergy, Asthma and Immunology, vol. 100, no. 4, pp. 351-357, 2008.

[32] P. M. Elias and M. Schmuth, "Abnormal skin barrier in the etiopathogenesis of atopic dermatitis," Current Allergy and Asthma Reports, vol. 9, no. 4, pp. 265-272, 2009.

[33] L. Ye, C. Lv, G. Man, S. Song, P. M. Elias, and M.-Q. Man, "Abnormal epidermal barrier recovery in uninvolved skin supports the notion of an epidermal pathogenesis of psoriasis," Journal of Investigative Dermatology, vol. 134, no. 11, pp. 28432846, 2014.

[34] S. Zia, A. Ndoye, T. X. Lee, R. J. Webber, and S. A. Grando, "Receptor-mediated inhibition of keratinocyte migration by nicotine involves modulations of calcium influx and intracellular concentration," Journal of Pharmacology and Experimental Therapeutics, vol. 293, no. 3, pp. 973-981, 2000.

[35] S. A. Grando, R. M. Horton, T. M. Mauro, D. A. Kist, T. X. Lee, and M. V. Dahl, "Activation of keratinocyte nicotinic cholinergic receptors stimulates calcium influx and enhances cell differentiation," Journal of Investigative Dermatology, vol. 107, no. 3, pp. 412-418, 1996.

[36] M. Denda, S. Fuziwara, and K. Inoue, "Influx of calcium and chloride ions into epidermal keratinocytes regulates exocytosis of epidermal lamellar bodies and skin permeability barrier homeostasis," Journal of Investigative Dermatology, vol. 121, no. 2, pp. 362-367, 2003.

[37] Z. Liu, J. W. Fluhr, S. P. Song et al., "Sun-induced changes in stratum corneum function are gender and dose dependent in a chinese population," Skin Pharmacology and Physiology, vol. 23, no. 6, pp. 313-319, 2010.

[38] S.-P. Song, C.-Z. Lv, K. R. Feingold et al., "Abnormalities in stratum corneum function in patients recovered from leprosy," Skin Pharmacology and Physiology, vol. 22, no. 3, pp. 131-136, 2009.

[39] J. Liu, W. Y. Man, C. Z. Lv et al., "Epidermal permeability barrier recovery is delayed in vitiligo-involved sites," Skin Pharmacology and Physiology, vol. 23, no. 4, pp. 193-200, 2010.

[40] A. Tfayli, D. Jamal, R. Vyumvuhore, M. Manfait, and A. BailletGuffroy, "Hydration effects on the barrier function of stratum corneum lipids: Raman analysis of ceramides 2, III and 5," Analyst, vol. 138, no. 21, pp. 6582-6588, 2013.

[41] J.-P. Hachem, T. Roelandt, N. Schürer et al., "Acute acidification of stratum corneum membrane domains using polyhydroxyl acids improves lipid processing and inhibits degradation of corneodesmosomes," Journal of Investigative Dermatology, vol. 130, no. 2, pp. 500-510, 2010.

[42] J.-P. Hachem, M.-Q. Man, D. Crumrine et al., "Sustained serine proteases activity by prolonged increase in $\mathrm{pH}$ leads to degradation of lipid processing enzymes and profound alterations of barrier function and stratum corneum integrity," Journal of Investigative Dermatology, vol. 125, no. 3, pp. 510-520, 2005.

[43] N. Muizzuddin, K. Marenus, P. Vallon, and D. Maes, "Effect of cigarette smoke on skin," Journal of Cosmetic Science, vol. 48, no. 5, pp. 235-242, 1997.

[44] K. Waterston, L. Naysmith, and J. L. Rees, "Physiological variation in the erythemal response to ultraviolet radiation and photoadaptation," Journal of Investigative Dermatology, vol. 123, no. 5, pp. 958-964, 2004.

[45] J. Singh, M. Gross, B. Sage, H. T. Davis, and H. I. Maibach, "Regional variations in skin barrier function and cutaneous irritation due to iontophoresis in human subjects," Food and Chemical Toxicology, vol. 39, no. 11, pp. 1079-1086, 2001.

[46] F. Ren, V. Rocchetti, M. Migliario, M. Rizzi, and M. Cannas, "Chronic exposure to cigarette smoke increases matrix metalloproteinases and Filaggrin mRNA expression in oral keratinocytes: role of nicotine stimulation," Oral Oncology, vol. 47, no. 9, pp. 827-830, 2011.

[47] H.-J. Lee, H.-Y. Guo, S.-K. Lee et al., "Effects of nicotine on proliferation, cell cycle, and differentiation in immortalized and malignant oral keratinocytes," Journal of Oral Pathology and Medicine, vol. 34, no. 7, pp. 436-443, 2005.

[48] C. Theilig, A. Bernd, A. Ramirez-Bosca et al., "Reactions of human keratinocytes in vitro after application of nicotine," Skin Pharmacology, vol. 7, no. 6, pp. 307-315, 1994.

[49] S. A. Grando, R. M. Horton, E. F. R. Pereira et al., "A nicotinic acetylcholine receptor regulating cell adhesion and motility is expressed in human keratinocytes," Journal of Investigative Dermatology, vol. 105, no. 6, pp. 774-781, 1995.

[50] L. Ashakumary and P. L. Vijayammal, "Additive effect of alcohol and nicotine on lipid metabolism in rats," Indian Journal of Experimental Biology, vol. 31, no. 3, pp. 270-274, 1993.

[51] M. S. Latha, P. L. Vijayammal, and P. A. Kurup, "Effect of nicotine administration on lipid metabolism in rats," Indian Journal of Medical Research-Section B: Biomedical Research Other Than Infectious Diseases, vol. 98, pp. 44-49, 1993.

[52] M. S. Latha, P. L. Vijayammal, and P. A. Kurup, "Effect of exposure of rats to cigarette smoke on the metabolism of lipids," Atherosclerosis, vol. 70, no. 3, pp. 225-231, 1988.

[53] T. C. Scharschmidt, M.-Q. Man, Y. Hatano et al., "Filaggrin deficiency confers a paracellular barrier abnormality that reduces inflammatory thresholds to irritants and haptens," Journal of Allergy and Clinical Immunology, vol. 124, no. 3, pp. 496-506, 2009.

[54] L. M. Sevilla, R. Nachat, K. R. Groot et al., "Mice deficient in involucrin, envoplakin, and periplakin have a defective epidermal barrier," Journal of Cell Biology, vol. 179, no. 7, pp. 1599-1612, 2007.

[55] O. S. Kwon, J. H. Chung, K. H. Cho et al., "Nicotine-enhanced epithelial differentiation in reconstructed human oral mucosa in vitro," Skin Pharmacology and Applied Skin Physiology, vol. 12, no. 4, pp. 227-234, 1999.

[56] K. R. Feingold, M. Mao-Qiang, G. K. Menon, S. S. Cho, B. E. Brown, and P. M. Elias, "Cholesterol synthesis is required for cutaneous barrier function in mice," The Journal of Clinical Investigation, vol. 86, no. 5, pp. 1738-1745, 1990.

[57] F. M. Moodie, J. A. Marwick, C. S. Anderson et al., "Oxidative stress and cigarette smoke alter chromatin remodeling but differentially regulate NF- $\kappa \mathrm{B}$ activation and proinflammatory cytokine release in alveolar epithelial cells," The FASEB Journal, vol. 18, no. 15, pp. 1897-1899, 2004. 
[58] F. Cervellati, X. M. Muresan, C. Sticozzi et al., "Comparative effects between electronic and cigarette smoke in human keratinocytes and epithelial lung cells," Toxicology in Vitro, vol. 28, no. 5, pp. 999-1005, 2014.

[59] G. K. Johnson and C. C. Organ, "Prostaglandin E2 and interleukin-1 concentrations in nicotine-exposed oral keratinocyte cultures," Journal of Periodontal Research, vol. 32, no. 5, pp. 447-454, 1997.

[60] A. Kode, S.-R. Yang, and I. Rahman, "Differential effects of cigarette smoke on oxidative stress and proinflammatory cytokine release in primary human airway epithelial cells and in a variety of transformed alveolar epithelial cells," Respiratory Research, vol. 7, article 132, 2006.

[61] C. O. Barland, E. Zettersten, B. S. Brown, J. Ye, P. M. Elias, and R. Ghadially, "Imiquimod-induced interleukin- $1 \alpha$ stimulation improves barrier homeostasis in aged murine epidermis," Journal of Investigative Dermatology, vol. 122, no. 2, pp. 330-336, 2004.

[62] Y.-J. Jung, M. Jung, M. Kim, S.-P. Hong, and E. H. Choi, "IL-1 $\alpha$ stimulation restores epidermal permeability and antimicrobial barriers compromised by topical tacrolimus," Journal of Investigative Dermatology, vol. 131, no. 3, pp. 698-705, 2011.

[63] C. Vestergaard, M. Hvid, C. Johansen, K. Kemp, B. Deleuran, and M. Deleuran, "Inflammation-induced alterations in the skin barrier function: implications in atopic dermatitis," Chemical Immunology and Allergy, vol. 96, pp. 77-80, 2012.

[64] M. Deleuran, M. Hvid, K. Kemp, G. B. Christensen, B. Deleuran, and C. Vestergaard, "IL-25 induces both inflammation and skin barrier dysfunction in atopic dermatitis," Chemical Immunology and Allergy, vol. 96, pp. 45-49, 2012.

[65] Y. Ido, A. Duranton, F. Lan, K. A. Weikel, L. Breton, and N. B. Ruderman, "Resveratrol prevents oxidative stress-induced senescence and proliferative dysfunction by activating the AMPK-FOXO3 cascade in cultured primary human keratinocytes," PLoS ONE, vol. 10, no. 2, Article ID e0115341, 2015.

[66] C. Sticozzi, F. Cervellati, X. M. Muresan, C. Cervellati, and G. Valacchi, "Resveratrol prevents cigarette smoke-induced keratinocytes damage," Food \& Function, vol. 5, no. 9, pp. 23482356, 2014.

[67] C. Sticozzi, G. Belmonte, A. Pecorelli et al., "Cigarette smoke affects keratinocytes $\mathrm{SRB} 1$ expression and localization via $\mathrm{H}_{2} \mathrm{O}_{2}$ production and HNE protein adducts formation," PLoS ONE, vol. 7, no. 3, Article ID e33592, 2012.

[68] M.-Q. Man, G. Man, and P. M. Elias, "Could psoriasis be preventable?” Dermatologica Sinica, vol. 33, no. 4, pp. 243-244, 2015.

[69] A. Dregan, J. Charlton, P. Chowienczyk, and M. C. Gulliford, "Chronic inflammatory disorders and risk of type 2 diabetes mellitus, coronary heart disease, and stroke: a population-based cohort study," Circulation, vol. 130, no. 10, pp. 837-844, 2014.

[70] C. Horreau, C. Pouplard, E. Brenaut et al., "Cardiovascular morbidity and mortality in psoriasis and psoriatic arthritis: a systematic literature review," Journal of the European Academy of Dermatology and Venereology, vol. 27, no. 3, pp. 12-29, 2013.

[71] J. I. Silverberg and P. Greenland, "Eczema and cardiovascular risk factors in 2 US adult population studies," Journal of Allergy and Clinical Immunology, vol. 135, no. 3, pp. 721-728, 2015.

[72] J. P. Thyssen, A. Linneberg, B. C. Carlsen et al., "A possible association between a dysfunctional skin barrier (filaggrin nullmutation status) and diabetes: A Cross-Sectional Study," The British Medical Journal, vol. 1, article e000062, 2011.
[73] H. Kurzen, C. Fademrecht, S. Goerdt, H. Seltmann, Ch. C. Zouboulis, and A. Gratchev, "Impact of acetylcholine on sebocyte biology in vitro," Experimental Dermatology, vol. 15, no. 6, pp. 643-648, 2006.

[74] J. W. Fluhr, M. Mao-Qiang, B. E. Brown et al., "Glycerol regulates stratum corneum hydration in sebaceous gland deficient (asebia) mice," Journal of Investigative Dermatology, vol. 120, no. 5, pp. 728-737, 2003.

[75] E. H. Choi, M.-Q. Man, F. Wang et al., "Is endogenous glycerol a determinant of stratum corneum hydration in humans?" Journal of Investigative Dermatology, vol. 125, no. 2, pp. 288-293, 2005. 


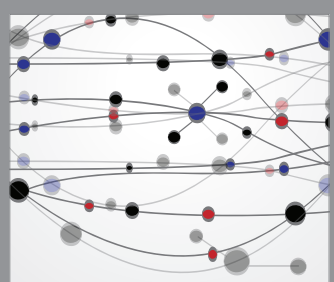

The Scientific World Journal
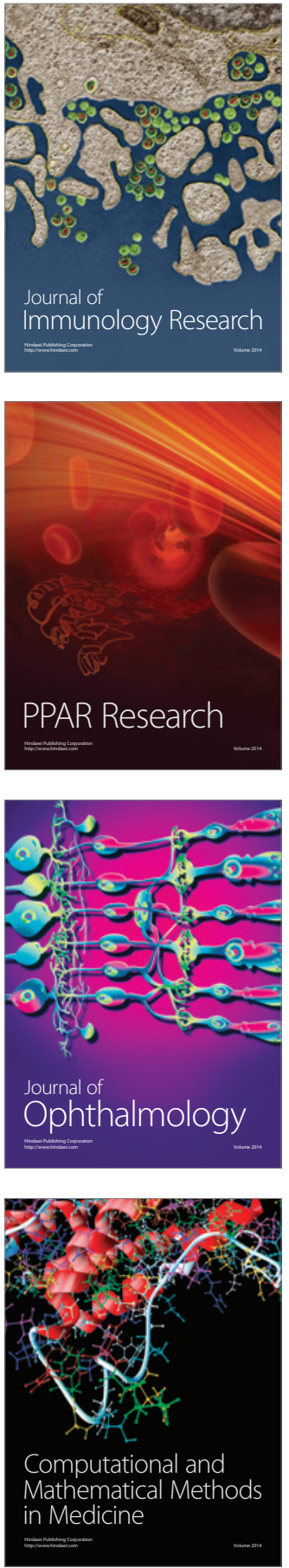

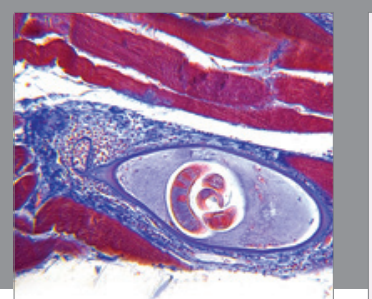

Gastroenterology Research and Practice

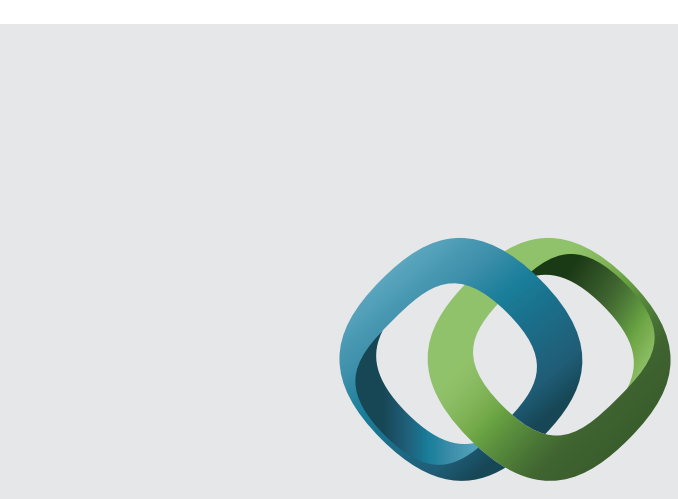

\section{Hindawi}

Submit your manuscripts at

http://www.hindawi.com
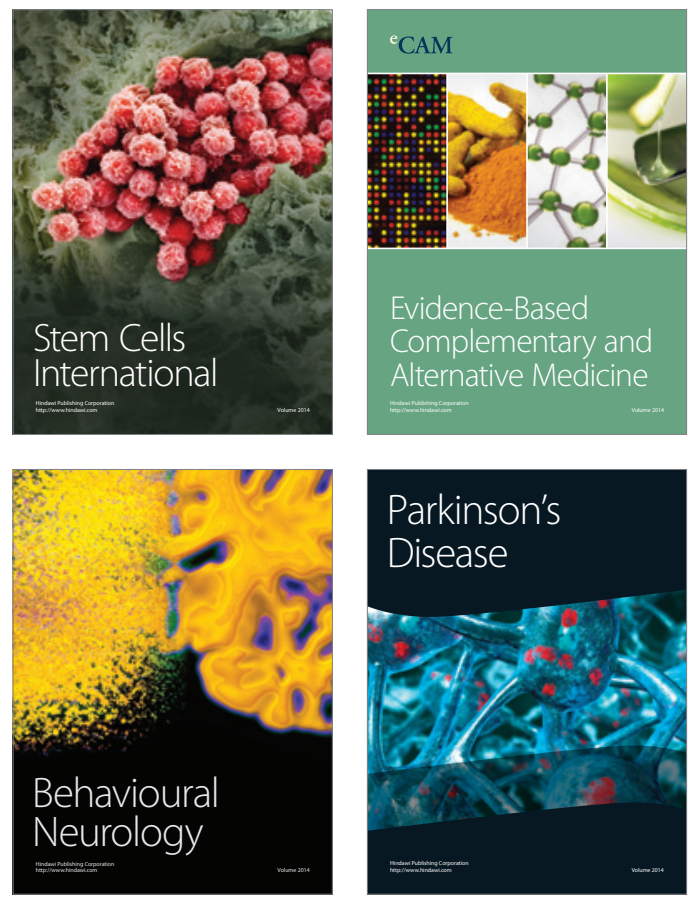
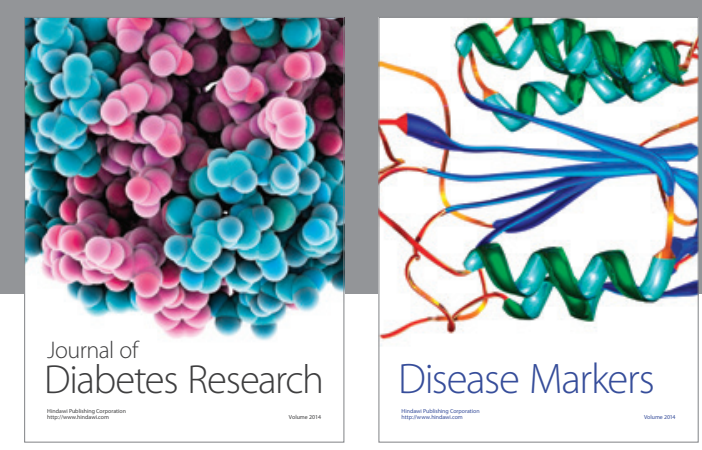

Disease Markers
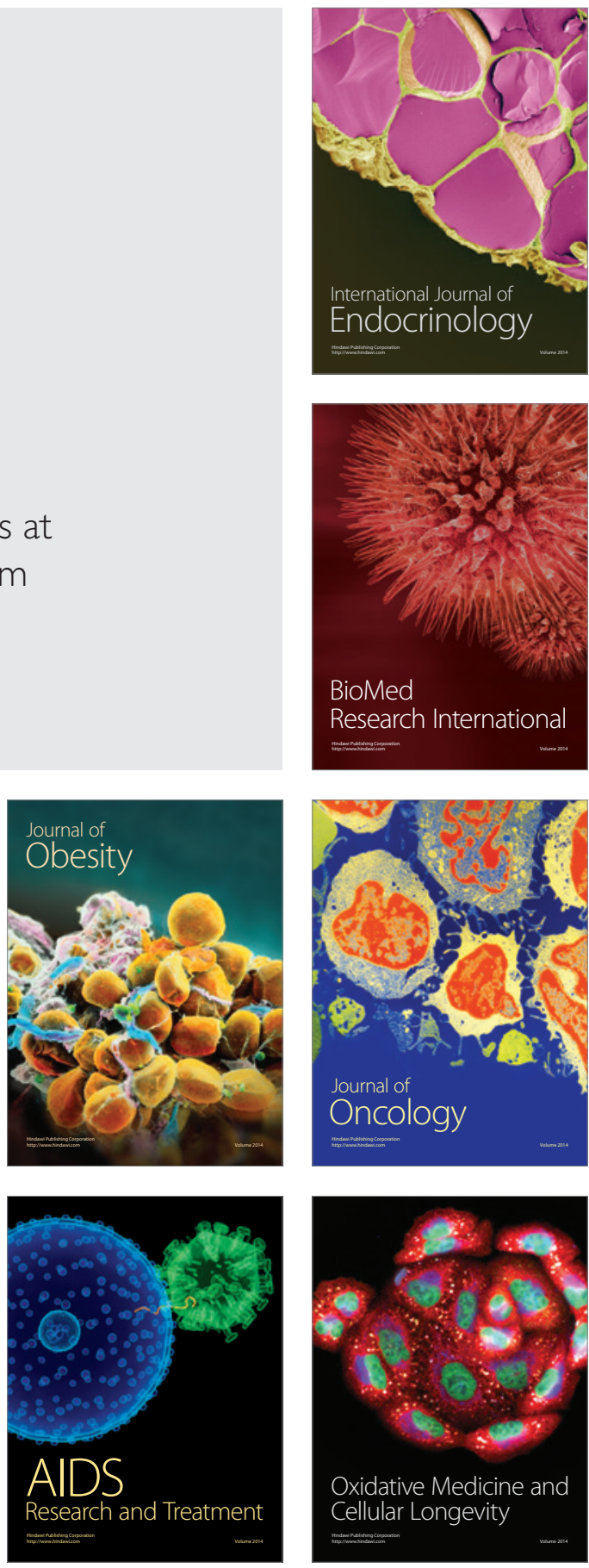